\title{
Influence of Betaxolol on the Methamphetamine Dependence in Mice
}

\author{
Byoung-Jo Kim ${ }^{1,2 *}$, Jong-II Park ${ }^{3,4 *}$, Hun-Jeong Eun ${ }^{1,2}$, and Jong-Chul Yang ${ }^{3,4} \bowtie$ \\ ${ }^{1}$ Department of Neuropsychiatry, Presbyterian Medical Center-Jesus Hospital, Jeonju, Republic of Korea \\ ${ }^{2}$ Department of Neuropsychiatry, Seonam University College of Medicine, Jeonju, Republic of Korea \\ ${ }^{3}$ Department of Psychiatry, Chonbuk National University Medical School, Jeonju, Republic of Korea \\ ${ }^{4}$ Research Institute of Clinical Medicine of Chonbuk National University-Biomedical Research Institute of Chonbuk National University Hospital, \\ Jeonju, Republic of Korea
}

\begin{abstract}
Objective The noradrenaline system is involved in the reward effects of various kinds of abused drugs. Betaxolol (BTX) is a highly selective $\beta_{1}$-antagonist. In the present study, we evaluated the effect of BTX on methamphetamine (MAP)-induced conditioned place preference (CPP) and hyperactivity in mice.

Methods The mice $(n=72)$ were treated with MAP or saline every other day for a total of 6 days (from day 3 to day 8; 3-times MAP and 3-times saline). Each mouse was given saline ( $1 \mathrm{~mL} / \mathrm{kg})$ or MAP ( $1 \mathrm{mg} / \mathrm{kg}$, s.c.) or BTX ( $5 \mathrm{mg} / \mathrm{kg}$, i.p.) or MAP with BTX (5 mg/kg, i.p.) $30 \mathrm{~min}$ prior to the administration of MAP $(1 \mathrm{mg} / \mathrm{kg}$, s.c.) every other day and paired with for $1 \mathrm{~h}$ (three-drug and three-saline sessions). We then compared the CPP score between the two groups. After the extinction of CPP, the mice were given BTX (5 mg/kg, i.p.) or saline (1 $\mathrm{mL} / \mathrm{kg}$ ) $24 \mathrm{~h}$ prior to a priming injection of MAP, and were then immediately tested to see whether the place preference was reinstated.

Results The repeated administration of BTX $30 \mathrm{~min}$ prior to the exposure to MAP significantly reduced the development of MAP-induced CPP. When BTX was administered $24 \mathrm{~h}$ prior to the CPP-testing session on day 9, it also significantly attenuated the CPP, but did not result in any change of locomotor activity. In the drug-priming reinstatement study, the extinguished CPP was reinstated by a MAP $(0.125 \mathrm{mg} / \mathrm{kg}$, s.c.) injection and this was significantly attenuated by BTX.

Conclusion These findings suggest that BTX has a therapeutic and preventive effect on the development, expression, and drug-priming reinstatement of MAP-induced CPP.

Psychiatry Investig 2016;13(3):316-320
\end{abstract}

Key Words Betaxolol, Methamphetamine, Conditioned place preference, Hyperactivity.

\section{INTRODUCTION}

Drug addiction has important biological, psychological, and social causes and consequences, and it has been recognized as a psychiatric disease that involves the development of complex behaviors such as tolerance, dependence, and cravings regarding drugs that are characteristic of an addictive state. Methamphetamine (MAP) has strong psychostimulant effects and a severe addictive property, and its abuse is a major health problem; moreover, MAP addiction has no corresponding

Received: February 21, 2015 Revised: June 12, 2015

Accepted: August 12, 2015 Available online: December 31, 2015

$\triangle$ Correspondence: Jong-Chul Yang, MD, PhD

Department of Psychiatry, Chonbuk National University Medical School, 20 Geonji-ro, Deokjin-gu, Jeonju 54907, Republic of Korea

Tel: +82-63-250-2580, Fax: +82-63-275-3157, E-mail: yangjc@jbnu.ac.kr

*These authors contributed equally to this work.

(a) This is an Open Access article distributed under the terms of the Creative Commons Attribution Non-Commercial License (http://creativecommons.org/licenses/bync/3.0) which permits unrestricted non-commercial use, distribution, and reproduction in any medium, provided the original work is properly cited. detoxification agent yet. ${ }^{1}$

Although the inhibition of dopamine (DA) uptake and the subsequent stimulation of DA receptors are established mechanisms that mediate the abuse-related effects of psychostimulants, existing evidence shows that noradrenaline (NE) uptake and NE-receptor mechanisms can also have important modulating roles regarding the behavioral effects of psychostimulants in laboratory animals. In pigeons, rats, and monkeys that have been trained to discriminate relatively low doses of cocaine from a vehicle, NE-transport inhibitors partially mimic the discriminative stimulus effects of cocaine, ${ }^{2-6}$ and when combined with cocaine or the selective DA-transport inhibitor GBR 12909, the NE-transport inhibitors enhanced these discriminative stimulus effects. ${ }^{2,6,7}$ Furthermore, the discriminative stimulus effects of cocaine and the cocaine-like effects of NE-transport inhibitors such as talsupram and tomoxetine can be attenuated by the alpha-adrenoceptor antagonist prazosin. ${ }^{4,6}$ Previous studies showed that those animal 
subjects that received the beta-adrenoceptor antagonist propranolol following a preference test showed no preference for the cocaine-paired floor during a subsequent test, whereas vehicle-treated rats continued to express a preference for the cocaine-paired floor. ${ }^{8}$ These results suggest that the propranolol induced an impairment with respect to drug-seeking behavior.

Since propanolol, which is both a $\beta 1$ - and $\beta 2$-adrenergic receptor antagonist, has a binding capability to $5-\mathrm{HT}$ (serotonin) receptors, ${ }^{9}$ and atenolol, a selective $\beta_{1}$ antagonist, enters the brain in very limited amounts, ${ }^{10}$ these drugs may affect MAPinduced CPP and hyperactivity via a blocking of the peripheral $\beta 1$-adrenergic receptors. ${ }^{11}$ To avoid the effect of the $\beta 1$ adrenergic receptor antagonist via the peripheral receptors, we used betaxolol (BTX) in our study since BTX easily crosses the blood-brain barrier. ${ }^{12}$ BTX is a highly selective $\beta_{1}$ antagonist with no partial agonist (intrinsic sympathomimetic) activity and weak membrane-stabilizing (local anaesthetic) activity. ${ }^{13}$ Place conditioning is commonly used to measure the rewarding or incentive properties of drugs, especially regarding psychological dependence. The conditioned place preference (CPP) model can therefore be used as an effective tool to investigate the underlying mechanisms of a drug-induced reinstatement of drug-seeking behavior after extinction, ${ }^{14}$ and can partly evaluate the associated learning ability. In the present study, we investigated the effect of BTX on MAP addiction with a sample of MAP-induced mice, whereby a CPP development, expression, and reinstatement model was used to elucidate the effect of BTX on drug addiction and relapse.

\section{METHODS}

\section{Animals}

Male ICR mice ( $\mathrm{n}=72$; aged from 4 weeks to 5 weeks; Samtako Bio, Korea) were used in the CPP test. All of the animals were maintained under a constant temperature of $22 \pm 2^{\circ} \mathrm{C}$, and were kept on a $12 \mathrm{~h}$ light/12 h dark cycle. Food (standard laboratory chow) and water were available ad libitum. All possible efforts were made to minimize animal suffering and the number of animals that were used, in accordance with the Chonbuk National University Medical School's "Guidelines for Animal Experiments."

\section{Apparatus}

The dimensions of the plexiglass CPP boxes measured $30 \times$ $15 \times 30 \mathrm{~cm}$-width (w), length (l), and height (h), respectively-and the insertion of a removable clipboard divided the boxes into two equal-sized compartments $(15 \times 15 \times 30 \mathrm{~cm})$. One compartment had black and white striped walls and a black grid floor (chamber A), and the other compartment had black walls and a smooth floor (chamber B). In our ex- perimental condition, the mice showed a significant spontaneous preference for chamber $\mathrm{A}$, and we therefore used a biased method, whereby chamber B served as the MAP-paired compartment. The entire experimental process was documented using a video tracking system (Smart-CS, Panlab, Spain)

\section{Procedures}

\section{Effect of BTX on development of MAP-induced CPP}

On the first day, each mouse habituated by freely exploring the two compartments for $20 \mathrm{~min}$ without any treatment. On the second day, we tested the natural preferences of the mice. The animal subjects were allowed to freely explore both compartments for $20 \mathrm{~min}$, and the compartment that was occupied for a lesser time was appointed as the drug-paired side (compartment B). The mice that received MAP were subjected to the least-preferred side. The biased method ${ }^{15}$ that we used meant that the MAP-paired compartment was initially the non-preferred side of the apparatus, as was measured during the pre-test. ${ }^{16}$

Between day 3 and day 8 , the mice were divided into four groups; each mouse was given saline $(1 \mathrm{~mL} / \mathrm{kg})$ or MAP (1 $\mathrm{mg} / \mathrm{kg}$, s.c.) or BTX (5 mg/kg, i.p.) or MAP with BTX (5 mg/ $\mathrm{kg}$, i.p.) $30 \mathrm{~min}$ prior to the administration of MAP (1 mg/ $\mathrm{kg}$, s.c.) on day 3, 5, 7 in compartment $\mathrm{B}$, and all mouse was given saline $(1 \mathrm{~mL} / \mathrm{kg})$ on day $4,6,8$ in compartment A. Methamphetamine (MAP) was purchased from Dainippon Sumitomo Pharma (Osaka, Japan). During the 6 days of the experiment, the locomotor activity of each group was also monitored. The behavior of the mice was recorded by a video camera and analyzed by Smart-CS system set (Panlab, Barcelona, Spain). On the test day (day 9), the animals were allowed free access to both compartments. The time spent in each compartment was recorded for $20 \mathrm{~min}$.

\section{Effect of BTX on established MAP-induced CPP}

To assess the blocking effect of BTX on MAP-induced CPP, each animal was conditioned with MAP ( $1 \mathrm{mg} / \mathrm{kg}$, s.c.) or saline $(1 \mathrm{~mL} / \mathrm{kg})$ without the pretreatment of BTX that was previously described. The mice were administered BTX (5 mg/ $\mathrm{kg}$, i.p.) or saline next day ( $24 \mathrm{~h}$ after) of the final conditioning. ${ }^{17} \mathrm{CPP}$ were then tested 2 day $(48 \mathrm{~h})$ after the final conditioning. ${ }^{18}$

\section{Effect of BTX on drug-priming reinstatement of MAP- induced CPP in mice}

Following the development of CPP, all of the mice were retested without any treatment every 2 days to examine the maintenance of CPP. Two days after determining the extinc- 
tion of CPP, ${ }^{16}$ they were given BTX (5 mg/kg, i.p.) or saline. After $24 \mathrm{~h}$, each animal was injected with a priming dose of MAP $(0.125 \mathrm{mg} / \mathrm{kg}$, s.c.) or saline and were immediately tested to see whether the CPP was reinstated.

\section{Statistical analysis}

Data are expressed as mean \pm SEM. The CPP score was calculated as the difference between the times spent in chamber $\mathrm{B}$ during the pre- and post-conditioning phases. The significance of the difference between the groups was determined by a one-way ANOVA, followed by either the Manny-Whitney U-test (between 2 groups) or the Kruskal-Wallis test (among 4 groups), using GraphPad Prizm 3.0 (GraphPad Software, U.S.) software, which was commercially available at the time of the experiment. Probability values $<0.05$ were considered significant.

\section{RESULTS}

In this experiment, we assessed the effect of BTX on the development of MAP-induced CPP in mice. The 3 pairings of MAP (1 mg/kg, i.p.) with the naturally non-preferred chamber induced significant conditioning for the MAP-paired chamber. There was a significant increase of the time spent in the MAP-paired chamber with respect to the control group that was treated with saline instead of MAP ( $<<0.05$; Kruskal-Wallis test). As shown in Figure 1, the pretreatment of BTX (5 mg/kg, i.p.) significantly blocked MAP (1 mg/kg, s.c.)-induced CPP ( $p<0.01$; Kruskal-Wallis test). On its own, the BTX was devoid of an effect regarding place preference at the dose employed in this study. One day after the 3 pairings with MAP ( $1 \mathrm{mg} / \mathrm{kg}$, s.c.), the time spent in the MAP-paired compartment was increased by approximately $18 \%$, meaning

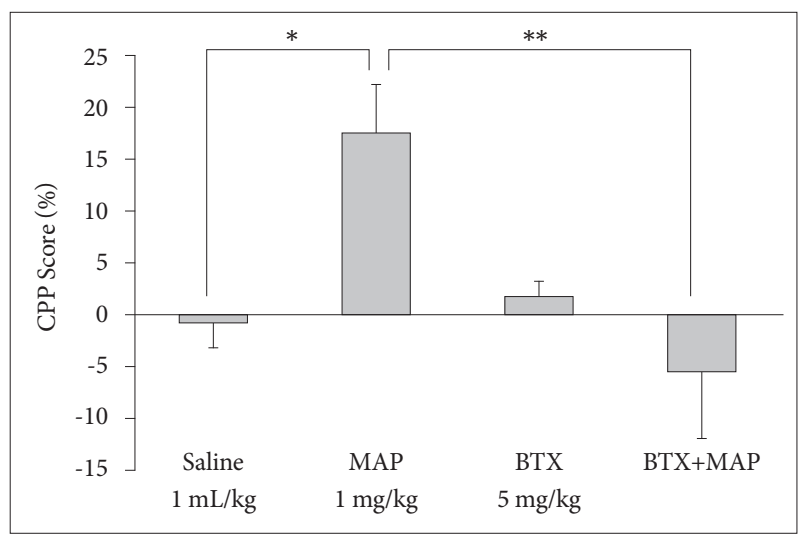

Figure 1. Effect of betaxolol (BTX, $5 \mathrm{mg} / \mathrm{kg}$, i.p.) on development of methamphetamine (MAP, $1 \mathrm{mg} / \mathrm{kg}$, s.c.) induced CPP in mice. Data are presented as mean \pm standard error of the mean (each group $\mathrm{N}=6) .{ }^{*} \mathrm{p}<0.05,{ }^{*} \mathrm{p}<0.01$. MAP+BTX: BTX (5 mg/kg, i.p.) injection 30 min prior to the MAP injection. CPP: conditioned place preference. that MAP-induced CPP was developed and maintained.

The repeated treatment of MAP gradually increased the locomotor activity of the mice, which was not affected by the BTX (Figure 2). Figure 2 shows that the repeated treatment of MAP or BTX+MAP displayed a significantly enhanced locomotion in response to the same dose of MAP on day 3 and day 5 compared with day 1 , indicating a behavioral sensitization. The BTX-or-saline-treated group did not show any sensitization across the test sessions ( $p>0.05$; one-way ANOVA). As indicated in Figure 3, the single administration of BTX ( $5 \mathrm{mg} / \mathrm{kg}$, i.p.) $24 \mathrm{~h}$ prior to the CPP test significantly attenuated the maintenance of MAP-induced CPP in the mice ( $\mathrm{p}<0.05$; Kruskal-Wallis test).

Three days after the extinction of CPP, the priming injection of MAP $(0.125 \mathrm{mg} / \mathrm{kg}$, s.c.) caused a reinstatement of place preference. Figure 4 shows that the pretreatment of

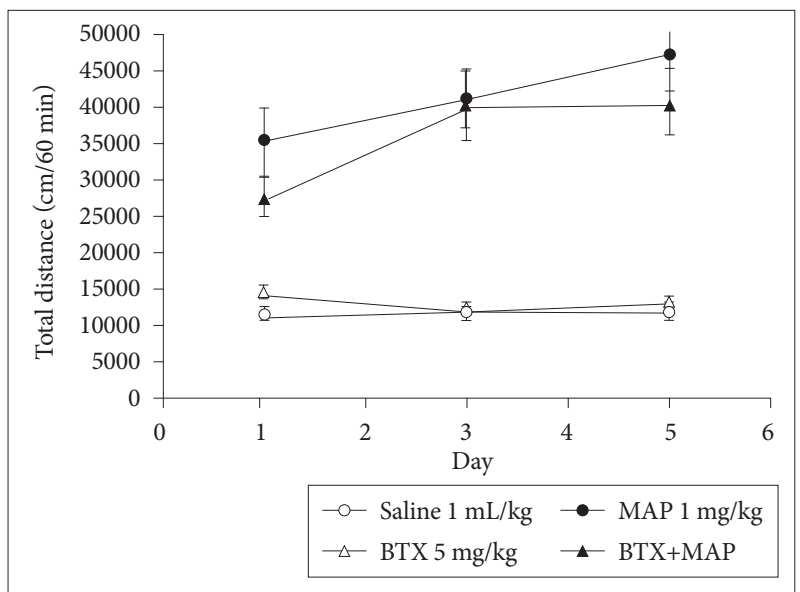

Figure 2. Effect of betaxolol (BTX, $5 \mathrm{mg} / \mathrm{kg}$, i.p.) on the methamphetamine-induced locomotor activity in mice. Data are presented as mean \pm standard error of the mean (each group $\mathrm{N}=6$ ).

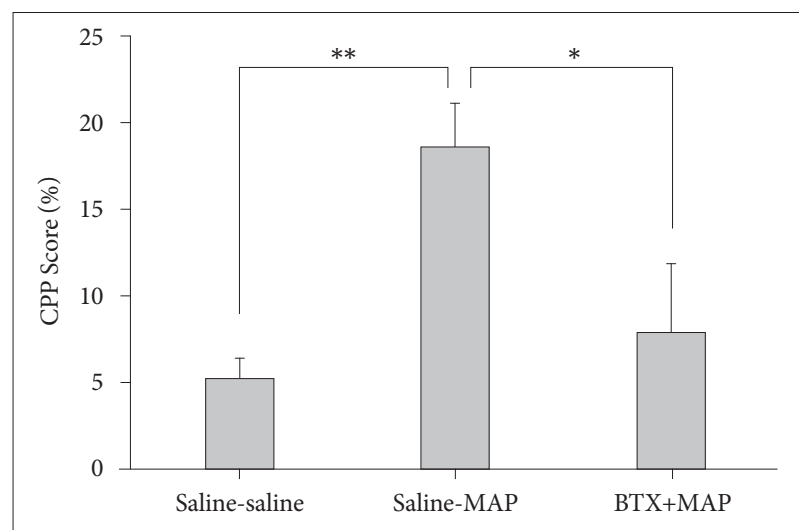

Figure 3. Effect of betaxolol (BTX, $5 \mathrm{mg} / \mathrm{kg}$, i.p.) on established methamphetamine (MAP, $1 \mathrm{mg} / \mathrm{kg}$, s.c.) induced CPP in mice. Data are presented as mean \pm standard error of the mean (each group $N=8$ ). ${ }^{*} p<0.05,{ }^{* *} p<0.01$. Saline-MAP: saline was injected $24 \mathrm{~h}$ prior to the CPP testing session, BTX-MAP: BTX was injected $24 \mathrm{~h}$ prior to the CPP testing session. CPP: conditioned place preference. 


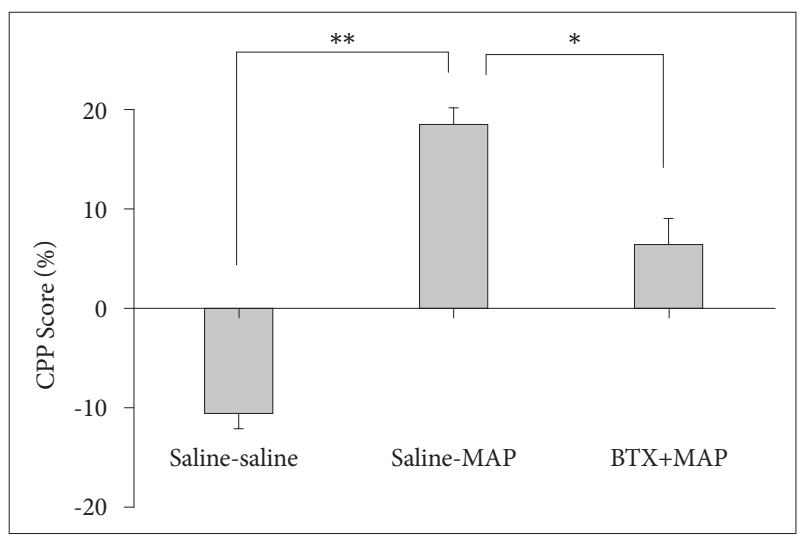

Figure 4. Effect of BTX (5 mg/kg, i.p.) on the reinstatement of CPP primed by methamphetamine (MAP, $0.125 \mathrm{mg} / \mathrm{kg}$, i.p.) in mice. Data are presented as mean \pm standard error of the mean (each group $\mathrm{N}=8$ ). ${ }^{*} \mathrm{p}<0.05,{ }^{* *} \mathrm{p}<0.001$. Saline-MAP: saline injection $24 \mathrm{~h}$ prior to the priming injection of MAP, BTX-MAP: BTX injection $24 \mathrm{~h}$ prior to the priming injection of MAP. CPP: conditioned place preference.

BTX (5 mg/kg, i.p.) significantly inhibited the reinstatement that was caused by the priming dose of MAP ( $<<0.001$; Kruskal-Wallis test).

\section{DISCUSSION}

In the present study, we examined the effect of the selective $\beta_{1}$ antagonist BTX on MAP-induced CPP. To our best knowledge, the influence of BTX on the rewarding properties of MAP has not been investigated in a research study. In our results, we demonstrate the role of BTX in the development and expression of MAP-induced CPP and hyperactivity. The CPP paradigm was widely studied in rodents, which previously showed of a place preference for compartment paired with drugs such as MAP, morphine, or cocaine. ${ }^{19,20}$ In our results, MAP induced a rewarding effect in the CPP paradigm while the locomotor activity was sensitized, which is also consistent with previous results. ${ }^{21-23}$ We found that administering BTX just prior (30 min) to the administration of MAP suppressed the development of MAP-induced place preference; however, when administered $30 \mathrm{~min}$ prior to a MAP injection, BTX did not result in any changes of locomotor activity. Also, we failed to find a BTX-induced place-preference effect, indicating that BTX has no rewarding properties. This result could suggest that BTX may play a significant role in blocking the primary rewarding properties of MAP, which supports the evidence regarding the role of NE mechanisms in the addictive effects of psychostimulants. In contrast to acquisition, the expression of MAP-induced place preference occurred in the absence of the primary rewarding stimulus, for example MAP, and instead relied on the motivational properties of the conditioned stimuli, for example environmental cue. In addition, the administration of BTX $24 \mathrm{~h}$ prior to the CPP test day also attenuated the expression of any previously established MAP-induced place preference. Our result is consistent with previous studies that reported that the rewarding effects of psychostimulant drugs were decreased with the administration of a beta-adrenergic receptor antagonist; specifically, propranolol disrupted place preferences that were conditioned to morphine ${ }^{24}$ and cocaine. ${ }^{8,17}$ The present finding supports the evidence that the efficacy of BTX in psychostimulant abuse is potentially associated with its effect on a $\beta 1$ adrenergic-receptor antagonism; ${ }^{25}$ however, the persistence of the BTX-induced attenuation of CPP for more than $24 \mathrm{~h}$ in our results remains unexplained.

Our result showed that a low dose of MAP $(0.125 \mathrm{mg} / \mathrm{kg})$, which produces no rewarding effects on its own, reinstated the extinguished place preference. However, we demonstrated that a MAP-induced reinstatement of CPP was significantly attenuated after pretreatment with BTX $24 \mathrm{~h}$ prior to the administration of MAP. Our findings are consistent with previous studies that showed that a morphine or cocaine injection reinstated an extinguished place preference; ${ }^{26-28}$ therefore, our present finding further confirms that drug priming is an important factor that is implicated in relapse.

The illicit psychostimulant drugs-cocaine and the amphetamines, as well as their derivatives-represent a highly addictive class of compounds; among these, a surge in the popular use of MAP has occurred. The psychological effects of MAP use are associated with anxiety, depression, psychosis, and suicide. ${ }^{29}$ MAP has various neurotoxic effects including a persistent depletion of dopamine, an inactivation of the dopamine transporter, an inhibition of tyrosine hydroxylase, the dysfunction of the vesicle monoamine transporter, the degeneration of fine unmyelinated axons, and apoptosis. ${ }^{30,31}$ MAP's neurotoxic effects on dopamine and serotonin neurons $\mathrm{s}^{32,33}$ are associated with the damage of brain regions such as the caudate, putamen, nucleus accumbens, substantia nigra, and hippocampus. ${ }^{34}$ In correspondence with an increased understanding of the mechanism of MAP use, a growing interest in the development of new pharmacological treatment options for treating MAP addiction and restoring neuronal function has emerged. We anticipate that our result may be elucidative with respect to these issues.

In conclusion, the present study suggests that the selective $\beta_{1}$ adrenoceptor is involved in the reward-processing mechanisms of drug abuse; furthermore, the selective $\beta_{1}$ adrenoceptor is also involved in the relapse to MAP craving. The selective $\beta_{1}$-adrenoceptor inhibitor may be a novel pharmacological target for the management of MAP abuse and relapse prevention; however, research still needs to elucidate whether these post-retrieval mechanisms are permanent or transient. 


\section{Acknowledgments}

This paper was supported by research funds of Chonbuk National University in 2011.

\section{REFERENCES}

1. Office of Justice Programs. 1995 Drug Use Forecasting Annual Report on Adult and Juvenile Arrestees. Washington DC: U.S. Department of Justice; 1996.

2. Cunningham KA, Callahan PM. Monoamine reuptake inhibitors enhance the discriminative state induced by cocaine in the rat. Psychopharmacology (Berl) 1991;104:177-180.

3. Baker LE, Riddle EE, Saunders RB, Appel JB. The role of mono-amine uptake in the discriminative stimulus effects of cocaine and related compounds. Behav Pharmacol 1993;4:69-79.

4. Johanson CE, Barrett JE. The discriminative Stimulus effects of cocaine in pigeons. J Pharmacol Exp Ther 1993;267:1-8.

5. Terry P, Witkin JM, Katz JL. Pharmacological characterization of the novel discriminative stimulus effects of a low dose of cocaine. J Pharmacol Exp Ther 1994;270:1041-1048.

6. Spealman RD. Noradrenergic involvement in the discriminative stimulus effects of cocaine in squirrel monkeys. J Pharmacol Exp Ther 1995; 275:53-62.

7. Kleven MS, Koek W. Discriminative stimulus properties of cocaine: enhancement by monoamine reuptake blockers. J Pharmacol Exp Ther 1998;284:1015-1025.

8. Bernardi RE, Lattal KM, Berger SP. Postretrieval propranolol disrupts a cocaine conditioned place preference. Neuroreport 2006;17:1443-1447.

9. Middlemiss DN, Blakeborough L, Leather SR. Direct evidence for an interaction of $\beta$-adrenergic blockers with the 5-HT receptor. Nature 1977:267-290

10. Agon P, Goethals P, Van Haver D, Kaufman J. Permeability of the bloodbrain barrier for atenolol studied by positron emission tomography. J Pharm Pharmacol 1991;43:597-600.

11. Harris GC, Aston-Jones G. Beta-adrenergic antagonists attenuate withdrawal anxiety in cocaine-and morphine-dependent rats. Psychopharmacology (Berl) 1993;113:131-136.

12. Swartz CM. Betaxolol in anxiety disorders. Ann Clin Psychiatry 1998; 10:9-14.

13. Beresford R, Heel RC. Betaxolol. A review of its pharmacodynamic and pharmacokinetic properties, and therapeutic efficacy in hypertension. Drugs 1986;31:6-28.

14. Parker LA, Mcdonald RV. Reinstatement of both a conditioned place preference and a conditioned place aversion with drug primes. Pharmacol Biochem Behav 2000;66:559-561.

15. Prus AJ, James JR, Rosecrans AJ. Methods of Behavioral Analysis in Neuroscience. Augusta: CRC press; 2000.

16. Li SM, Yin LL, Shi J, Lin ZB, Zheng JW. The effect of 7-nitroindazole on the acquisition and expression of D-methamphetamine-induced place preference in rats. Eur J pharmacol 2002;435:217-223.

17. Bernardi RE, Ryabinin AE, Berger SP, Lattal KM. Post-retrieval disruption of a cocaine conditioned place preference by systemic and intrabasolateral amygdala $\beta 2$ - and $\alpha 1$-adrenergic antagonists. Learn Mem 2009;
16:777-789.

18. Ma X, Zhang JJ, Yu LC. Post-retrieval extinction training enhances or hinders the extinction of morphine-induced conditioned place preference in rats dependent on the retrieval-extinction interval. Psychopharmacology (Berl) 2012;221:19-26.

19. Suzuki T, Tsuji M, Ikeda H, Misawa M, Narita M, Tseng LF. Antisense oligodeoxynucleotide to delta opioid receptors blocks cocaine-induced place preference in mice. Life Sci 1997;60:283-288.

20. Tzschentke TM. Measuring reward with the conditioned place preference paradigm: a comprehensive review of drug effects, recent progress and new issues. Prog Neurobiol 1998;56:613-672.

21. Li P, Rowshan K, Crisostomo M, Tjen-A-Looi SC, Longhurst JC. Effect of electroacupuncture on pressor reflex during gastric distension. Am J Physiol Regul Integr Comp Physiol 2002;283:1335-1345.

22. Li SM, Ren YH, Zheng JW. Effect of 7-nitroindazole on drug-priming reinstatement of D-methamphetamine-induced conditioned place preference. Eur J Pharmacol 2002;443:205-206.

23. Fujii H, Ishihama T, Ago Y, Shintani N, Kakuda M, Hashimoto H, et al. Methamphetamine-induced Hyperactivity and behavioral sensitization in PACAP deficient mice. Peptides 2007;28:1674-1679.

24. Robinson MJ, Franklin KB. Central but not peripheral beta-adrenergic antagonism blocks reconsolidation for a morphine place preference. Behav Brain Res 2007;182:129-134.

25. Rudoy CA, Van Bockstaele EJ. Betaxolol, a selective beta(1)-adrenergic receptor antagonist, diminishes anxiety-like behavior during early withdrawal from chronic cocaine administration in rats. Prog Neuropsychopharmacol Biol Psychiatry 2007;31:1119-1129.

26. Fricks-Gleason AN, Marshall JF. Post-retrieval b-adrenergic receptor blockade: effects on extinction and reconsolidation of cocaine-cue memories. Learn Mem 2008;15:643-648.

27. Lu L, Huang M, Ma L, Li J. Different role of cholecystokinin (CCK)-A and CCK-B receptors in relapse to morphine dependence in rats. Behav Brain Res 2001;120:105-110.

28. Mueller D, Stewart J. Cocaine-induced conditioned place preference: reinstatement by priming injections of cocaine after extinction. Behav Brain Res 2000;115:39-47.

29. Darke S, Kaye S, McKetin R, Duflou J. Major physical and psychological harms of methamphetamine use. Drug Alcohol Rev 2008;27:253-262.

30. Davidson C, Gow AJ, Lee TH, Ellinwood EH. Methamphetamine neurotoxicity: necrotic and apoptotic mechanisms and relevance to human abuse and treatment. Brain Res Brain Res Rev 2001;36:1-22.

31. Jayanthi S, McCoy MT, Ladenheim B, Cadet JL. Methamphetamine causes coordinate regulation of Src, Cas, Crk, and the Jun N-terminal kinase-Jun pathway. Mol Pharmacol 2002;61:1124-1131.

32. Malenka RC, Nestler EJ, Hyman SE. Reinforcement and Addictive Disorders. In: Sydor A, Brown RY, Editor. Molecular Neuropharmacology: A Foundation for Clinical Neuroscience 2nd Ed. New York: McGraw-Hill Medical; 2009.

33. Sekine Y, Ouchi Y, Takei N, Yoshikawa E, Nakamura K, Futatsubashi M, et al. Brain serotonin transporter density and aggression in abstinent methamphetamine abusers. Arch Gen Psychiatry 2006;63:90-100.

34. Kuhn DM, Angoa-Pérez M, Thomas DM. Nucleus accumbens invulnerability to methamphetamine neurotoxicity. ILAR J 2011;52:352-365. 